\title{
The method of using current regulations and standards in designing management and technologies of construction
}

\author{
Sergey Sinenko* \\ Moscow State University of Civil Engineering, Department of Construction Technology and \\ Organization, 129337 Moscow, Russian Federation
}

\begin{abstract}
Economic efficiency of using funds in construction of buildings and structures begins from an effective, proper design, which is based on modern, cutting-edge, advanced equipment, streamlined organization and process solutions of construction operations. In the light of this it is considered application of "Self-Organization and Technology of Building" multifunctional software package capable of solving various engineering tasks on designing management of construction operations in accordance with the applicable rules and regulations in view of using software for automatic generation of workflow. Implementing this software in the construction management processes may help to solve management tasks at the construction site.
\end{abstract}

\section{Normative study of designing management of construction operations}

Designing management of construction operations involves choosing the most effective management and process scheme of construction of buildings and structures, as well as application of contemporary process solutions for construction and installation which on the one hand should reduce estimated cost of construction and installation, as well as construction period of a facility, and on the other hand should provide high-quality construction in compliance with safety requirements, occupational safety, fire and environmental safety, in accordance with applicable rules, regulations and standards [1].

In the current context of present-day competition improvement the principal participants of investment and construction activities shall effectively arrange construction operations to receive maximum profit at minimal cost of time and resources without any failures as to construction deadlines causing expenses increasing in the course of projects implementation and loss of profit for all participants of construction and investment activities.

At present the market offers a majority of universal software packages that we are used to subdivide into professional and "desktop" (amateur). They mainly differ in the labour intensity when applying since professional software is quite time-consuming however it

\footnotetext{
*Corresponding author: 6622040@mail.ru
} 
may provide more flexible outcome, and amateur packages may be used just once, and spending little time and few efforts you shall receive quite an informative result.

Further, designing process of construction operations involves choosing the most efficient process solutions and the use of up-to-date devices that improve quality of construction products while reducing the time and cost of construction. Software market offers various products that can solve such tasks, but often they are not comprehensive enough $[2,3]$.

\section{The method of designing management}

\subsection{Justification of choosing the software}

It's offered a contemporary way to use current standards and specifications to meet the challenges of construction management and technologies: using the "Self-Organization and Technology of Building" ("SOTB") software. This software allows independent solving tasks in construction process management with the use of up-to-date technologies.

Self-Organization and Technology of Building is a multifunctional software package for solving tasks of construction operations management with the use of updated regulations. The software is also intended for the design of construction technologies: "SOTB" allows monitoring the progress of construction in real time.

The software is multifunctional and involves the following: financial planning; automatic generation of calendar and resource plans; maximizing the level of construction management; possibility to avoid unplanned costs, thereby increasing the profitability of construction companies [4].

\subsection{Components of the software package}

"SOTB" software consists of several components that interact with each other. Currently, there are 4 elements represented at the Figure 1, each of which has its own characteristics and meets certain requirements, which generally allow the software working smoothly and effectively.

\section{"Self-0rganization and Technology of Building" software's SE C T I O N S}

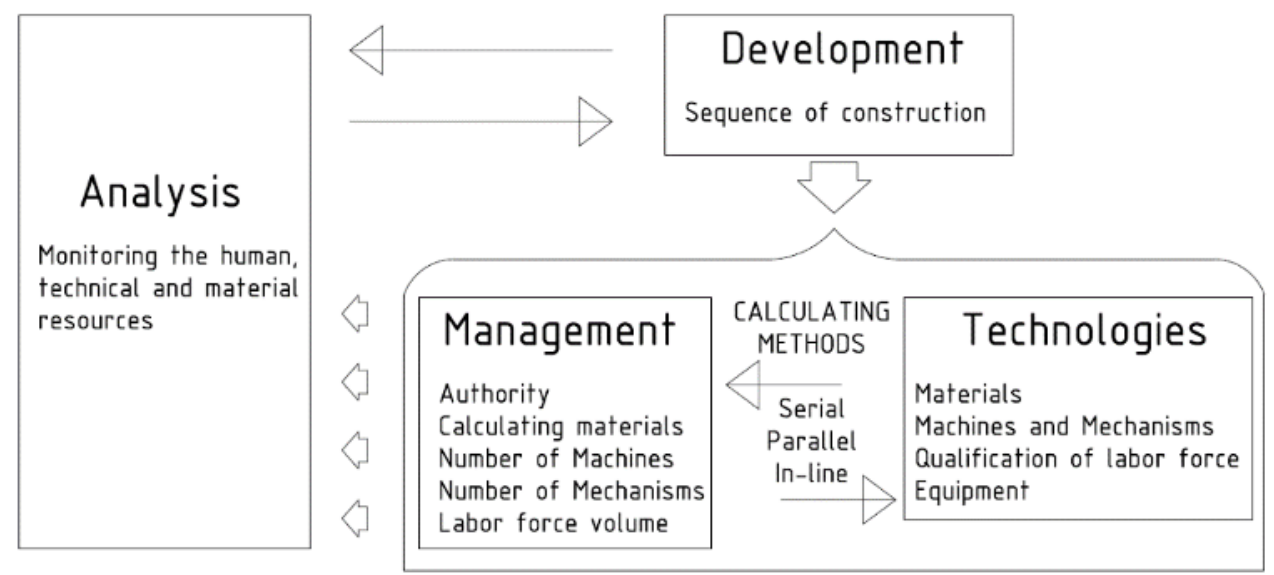

Fig. 1. "Self-Organization and Technology of Building" software's sections. 
Self-Organization and Technology of Building is, first of all, proper management and technology of construction operations. The management section of the software is a table into which we enter a construction site data.

"SOTB" displays the necessary building codes and state standards, while, in addition to the regulatory framework, the software automatically opens a new tab with authorities where a company should register documents. Also, "Management" section has an additional function for calculating the necessary materials, the number of machines and mechanisms, and finding the labour force volume needed.

"SOTB" software package offers construction methods being the most appropriate for a given amount of work. "SOTB" independently calculates three methods of construction and installation works (serial, parallel and in-line), thus allowing the customer choosing the most suitable and profitable one.

In Development section "SOTB" offers approval of construction operations sequence. Since the sequence can be attributed both to management, and to technologies, the software developers found it appropriate to make "Development" section and to make a sequence of construction and installation a separate item.

"SOTB" users can make any changes in this section, and their proposals will be automatically updated in "Technologies" and "Management" sections. Changing a sequence may for example changing the materials to be more exact, timing of their delivery to a construction site or workers' involvement may partially change or the use of machines and equipment.

The main and more important aspect is the ability of "SOTB" to identify equipment, construction machinery downtime, or non-rational employment of workers. For this purpose, the software contains the fourth element the "Analysis".

Analysis section is on a paying basis, but, despite this, the majority of users buy this optional item to have the whole software. "Analysis" allows monitoring the use of human, technical and material resources. Also, this section includes a part of financial policy, thus clearly shows the costs and revenue of a company from using each of the methods of construction and installation works $[5,6]$.

The software is multifunctional and involves the following: financial planning; automatic generation of calendar and resource plans; maximizing the level of construction management; possibility to avoid unplanned costs, thereby increasing the profitability of construction companies [4].

\subsection{Focus areas of the software package}

"SOTB" allows preparing construction operations in two areas: preparation for a facility construction and preparation of construction and installation management.

\subsubsection{Management preparation}

The Management Preparation includes justification, approval, obtaining a building permit which is regulated for example in Russia by "The order of development, coordination, approval and composition of studies of investments in construction of enterprises, buildings and structures..." [7].

The Management Preparation includes engineering research, development of design estimates, ordering equipment. "SOTB" will allow developing design \& estimate documentation, choosing the most efficient option of using the equipment, and also functions of the software include a list of authorities that will provide the necessary material and technical resources within the given timeframe.

Technical preparation is divided into: 
- off-site preparation;

- on-site preparation;

- facility preparation.

Off-site preparation includes providing access roads, supply lines and networks, in some cases, this includes creating a base. On-site preparation includes creating a geodetic control network, arrangement of roads, construction site fencing, and providing communication. Facility preparation is a breakdown of axes of buildings, fixing, delivery of materials, cranes installation.

"SOTB" software is directly responsible for technical preparation. After entering certain data (overall size of the building, of the construction site and location of the building relative to the construction site), it designs temporary supply lines to the building, parameters of which have already been entered into the software.

Also, Self-Organization and Technology of Building offers recommended location of temporary roads, places for storage of materials, equipment installation location (the software designs all these based on the documents responsible for compliance with the rules at the facility and at the construction site generally). The software also has a "Preferences" feature, where you can manually change one or more parameters; in this case, "SOTB" will offer a different design of the facility, taking into account the customer's preferences [8].

\subsubsection{Process preparation and realization}

Process preparation is to implement the solutions contained in the Work performance projects (in the Process charts).

Self-Organization and Technology of Building software develops operations and financial plan for a company in its key activities and based on the following:

- Plan of the construction facility;

- Plan of the construction operations;

- Technical development plan;

- Mechanization plan;

- Labour plan;

- Procurement plan;

- Profit and cost plan;

- Income and expenses plan.

All of these plans are based on the main principles of term scheduling and supervising [9].

\subsubsection{Term scheduling and supervising}

Timeline analysis procedures provided by "SOTB" enable to estimate the project's total duration, any possible earlier date of completing thereof, dates of the project's goals start and finish, time reserves and to identify critical tasks.

To perform the timeline analysis, it's required the estimations of the project goals duration. Such parameter may be directly set for work or may be calculated. In certain spheres, for instance, in construction the project shall be initially planned not subject to the works duration but subject to the scope thereof.

In "SOTB" software such principle shall be realized by estimating the duration subject to assigned resources or an algorithm set by a user. It may be used probability estimates received as the result of the risks analysis. Reflecting the project's critical path may be made possible by several means including colouring on the screen or receiving reports providing the information only regarding the critical path goals. 


\subsubsection{Resources planning}

One of the key differences of any system for scheduling is the type of resources to be supported and the way the resources management process is implemented in a multiproject. All the majority of resources types in the context of pattern description of scheduling goals reasonably are subdivided into two key types (renewable - reproduced, non-stock or being stored - resources distinguished by an ability to be compensated in case of any idle time; nonrecoverable - those being wasted completely changing their actual form and excluding repeated use).

"SOTB" is capable of considering such resources types and may take into account the kind of "perishable resources" that we may be storing for a fixed period, and upon expiration thereof unused odds shall not be transferred to the following intervals and are simply lost.

"SOTB is also capable of considering the resources with various qualifications list including selecting the least loaded resource in the course of the work fulfilment [10].

\subsubsection{Analysing the resources provided for the project's works}

"SOTB" offers powerful features to analyse the extent of the project's coverage by resources by means of comparing their demand's profiles and availability thereof in the course of the project implementation. Such analysis may be made both for a separate resource and for any group thereof.

"SOTB" As opposed to many other scheduling packages program enables to perform analysis and rescheduling not only for renewable resources but also for physical ones providing for this purpose two basic methods for dates estimation in the course of resource planning: in the context of limited time and limited resources [11].

\subsubsection{Costs planning and supervising}

Supervising any monetary assets expended in the course of the project implementation is one of the key goals in the project being no less important than resources management. Though the functions of costs supervising are provided by the majority of packages for projects management using thereof quite seldom gives satisfactory results: mainly this is due to the fact that the offered cost functions disagree with a wide range of methods applied in a company for costs planning, tracking and statements making.

"SOTB" operations functions regarding the costs have been developed to secure basic procedures of cost supervision and appear to be a flexible mechanism that managers and schedulers shall as close as possible adapt for the environment they face [12].

\subsubsection{Analysing the works cost based on the actual output}

It is deemed not practical to track only the difference between the amounts planned for the works fulfilment and the actual amounts since the simple comparison of the two figures upon the works completion shall be of no help for management and supervising. The very actual and planned costs do not provide a manager enough information if the non-fulfilled work has exceeded the budget.

Processing the costs data together with the actual achievements in "SOTB" is entitled "earned value cost control system" being analysing the works cost on the basis of actual output. As a rule, the aforementioned three parameters are depicted as aggregate costs curves in graphic form. The three parameters taken together, being the Planned cost of Scheduled works, the Planned cost of the Fulfilled works, the Actual cost of the Fulfilled works, shall form the core of the costs control system based on actual output $[13,14]$. 


\section{Software package application}

Self-Organization and Technology of Building software greatly facilitates solving management tasks at the construction site. Implementing this software in the construction management processes may help to avoid many complexities and details, among the house erecting could be planned using the newest materials and technologies.

The great advantage of the software is the regulatory framework, being the basis of "SOTB" including the basic regulations for management and technologies of construction operations. It makes it possible to implement the most rational construction process.

After the beta-release the "SOTB" software will be also applied on the professional practice level to the educational process and scientific research activity in Moscow State University of Civil Engineering at the Department of Construction Technology and Organization.

\section{Conclusion}

From this it could be concluded that every type of work has its own management and process aspects and therefore using Self-Organization and Technology of Building software with functional ability of managing each of construction process automates the search for the construction regulatory framework.

The "SOTB" software was designed and developed by Sergey Sinenko with the aim of making possible to solve various engineering tasks on designing management of construction operations by dint of creating an independent algorithm of works by entering input data and parameters of the facility, to obtain the documents mentioned in "Management" section, and follow automatic creation of workflow.

\section{References}

1. S.O. Novikov, A.A. Sapukhin, Proc. of MSUCE 7, 96 (2013)

2. A.A. Volkov, V.O. Chulkov, R. Kazaryan, M.A. Fachratov, O.N. Kyzina, R.K. Gazaryan, AMM 580, 2281 (2014)

3. V.S. Semenov, E.V. Tkach, S.A. Tkach, T.A. Rozovskaya, Proc. Eng. 111, 763 (2015)

4. B.V. Zhadanovsky, S.A Sinenko, Science Review 9-2, 435 (2014)

5. S.O. Novikov, B.V. Zhadanovsky, Science Review 21, 341 (2015)

6. B.V. Zhadanovsky, S.A. Sinenko, AMR 838-841, 280 (2013)

7. The Russian Government, Set of Rules 11-101-95 (Russian newspaper, 2011)

8. P.P. Oleinik, Proc. Eng. 153, 208 (2016)

9. V.O. Chulkov, R.K. Gazaryan, V. M. Fakhratov, A.V. Belyaev, Proc. of VGASU 23, $91(2012)$

10. E.K. Zavadskas, T. Vilutienè, Z. Turskis, J. Šaparauskas, ACME 14, 114 (2014)

11. D. Jato-Espino, E. Castillo-Lopez, J. Rodriguez-Hernandez, J.C. Canteras-Jordana, AutoCon 45, 151 (2014)

12. S.O. Novikov, Matec Web of Conf. 86, 04032 (2016)

13. A.A. Lapidus, Proc. of MSUCE 7, 96 (2013)

14. P. De Wilde, D. Coley, Build. and Env. 55, 1 (2012) 